\title{
Effects of self-irradiation in plutonium alloys
}

\author{
B.W. Chung*, K.E. Lema, and P.G. Allen \\ Lawrence Livermore National Laboratory \\ P.O. Box 808, Livermore, CA 94551, USA
}

\begin{abstract}
In this paper, we present updated results of self-irradiation effects on ${ }^{238} \mathrm{Pu}$-enriched ${ }^{239} \mathrm{Pu}$ alloys measured by immersion density, dilatometry, and tensile tests. We obtained the self-irradiation equivalent time of nearly 200 years, nearly 100 years longer than in our previous papers. At this extended aging, we find the rate of decrease in density has slowed significantly, stabilizing around $15.73 \mathrm{~g} / \mathrm{cc}$, without signs of void swelling. The volume expansion measured at $35^{\circ} \mathrm{C}$ also shows apparent saturation at less than $0.25 \%$. Quasi-static tensile measurement still show gradual increase in the strength of plutonium alloys with age.
\end{abstract}

*Corresponding author. Tel.: 1925 4233896; fax; 1925 4242491: e-mail; chung7@1lnl.gov

\section{Introduction}

Research on self-irradiation effects on plutonium $(\mathrm{Pu})$ and its alloys is a topic of continuing interest and is an important consideration in safe storage of these radioactive materials [1-16]. Plutonium and its alloys, when stored, accumulate radiation defects caused by self-irradiation damage which alter the underlying material microstructure, which leads to self-irradiation induced changes in physical and mechanical properties. 
The primary aging effects are believed to be lattice damage, helium bubble in-growth, and potential void swelling. The corresponding consequences to $\mathrm{Pu}$ metal include potential reduction in density, dimensional swelling, hardening, and embrittlement $[2,3$, 16].

Radiation damage from alpha decay in plutonium occurs at a rate of $\sim 0.1 \mathrm{dpa}$ (displacement per atom) per year. Because the effects of interest occur over decades, our approach is to accelerate the effects of radiation damage in Pu metal by adding small amount of the higher specific activity isotope ${ }^{238} \mathrm{Pu}$ into the ${ }^{239} \mathrm{Pu}$ lattice. This short-living

${ }^{238} \mathrm{Pu}$ isotope with the half-life of 87 years will accelerate the decay and self-irradiation to forecast the behavior of Pu metal. The objective of this work is to assess the impact of extended aging on the quasi-static properties of $\mathrm{Pu}$ alloys. Changes in quasi-static density and quasi-static mechanical properties at ambient temperature and pressure are expected due to the aging process. Past results have shown gradual decrease in density, increase in strength, and expansion in volume of plutonium alloys due to aging $[5,8-10,16]$. In this paper we update changes in both density and mechanical properties of plutonium alloys due to aging.

\section{Experimental}

Physical property tests have been performed on the delta-phase ${ }^{239} \mathrm{Pu}$ samples with compositions of $\sim 2$ atomic $\%$ of gallium. The samples initially contained 7.3 atomic $\%$ ${ }^{238} \mathrm{Pu}$ isotope in order to accelerate the self-irradiation [10]. This small amount of ${ }^{238} \mathrm{Pu}$ initially accelerated the self-irradiation process by the factor of nearly 18 compared to $\mathrm{Pu}$ alloys without enrichment. This rate of the acceleration decreases as the amount of ${ }^{238} \mathrm{Pu}$ 
isotope decreases over time, reaching to the factor of $\sim 17$ near 200 equivalent years of aging. Details of sample preparation and operation of the dilatometer system and immersion density techniques are presented elsewhere [10], so only a brief description is provided here.

Specifically designed dilatometers were set up inside a nitrogen atmosphere glovebox to monitor long-term growth resulting from the lattice damage and helium in-growth in ${ }^{238} \mathrm{Pu}$-enriched alloys[8]. Each dilatometer unit consists of a sample vacuum chamber fitted with linear variable differential transducers (LVDTs). An LVDT measures minute changes, 0.1 micron or less, in the position of a push-rod by monitoring changes in the inductance of a detector coil. In the current design, the detector coil is placed outside of the sample chamber. Two different lengths $(2$ and $3 \mathrm{~cm}$ ) of alloy specimens are used to differentiate between surface oxidation and volumetric swelling in the materials[10]. These specimens are placed in the copper well located inside the dilatometer system filled with helium at $35^{\circ} \mathrm{C}$ storage temperatures. A reference low thermal expansion glass (Zerodur) is also placed in the copper well to monitor the stability of the dilatometry system. The glovebox atmosphere is nitrogen and it is maintained to within $\pm 0.5^{\circ} \mathrm{C}$. The dilatometer and amplifier are maintained by cooling water to within $\pm 0.1^{\circ} \mathrm{C}$. Stability of measurement over a 120 day period is found to be better than $\pm 0.10 \mu \mathrm{m}$.

The immersion density equipment closely matches a design used by Bowman et al. $[8,10,17]$ and uses about $200 \mathrm{ml}$ of Fluorinert Electronic Liquid FC-43 as the immersion fluid. Prior to use, the system is calibrated using NIST glass (SRM 1827A). The calibration is verified after measurements. Because ${ }^{238} \mathrm{Pu}$-enriched alloys generate heat, a test sample is left overnight in the immersion bath to allow the temperature of the 
bath to stabilize and the measurements to be reproducible. A correction needs to be

applied to the measured density to compensate for the heat generated by the ${ }^{238} \mathrm{Pu}-$ enriched sample. Details of density correction are described elsewhere [10].

Each tensile test specimen was dimensionally inspected for the gage diameter $(\sim$ $15.2 \mathrm{~mm}$ ) and its length (GL), and loaded into a specially designed fixture for the tensile test. With a $6.1 \mathrm{~mm}$ GL extensiometer for the strain measurement, all testing was performed at room temperature with crosshead speed of $1.27 \mathrm{~mm} / \mathrm{min}$, so that the ultimate strain rate was about $3.5 \times 10^{-3} / \mathrm{sec}$. Aluminum specimens of known tensile strength were tested to verify the equipment integrity before and after each test specimen. The load and displacement data was recorded on a computer using the Instron Series IX software package in conjunction with an Instron Model 4444 test machine. Data was recorded from preloading until failure.

\section{Results and Discussion}

\subsection{Dilatometry and immersion density}

Figure 1 shows the volume change $(\Delta \mathrm{V})$ normalized with the initial volume $\left(\mathrm{V}_{\mathrm{o}}\right)$ of enriched alloys, as a function of equivalent age. The time is represented as an equivalent time (in years) obtained by multiplying the measurement time by the calculated accelerating factor (e.g. an average factor of 17). This accelerating factor is obtained by the $\alpha$-decay activities of the ${ }^{238} \mathrm{Pu}$-enriched alloy normalized by the decay activities of the reference alloy using the concentration of isotopes in each alloy. This factor will decrease as the material ages due primarily to decreasing concentration of ${ }^{238} \mathrm{Pu}$ in the specimen. Each dilatometer contains a pair of long $(3 \mathrm{~cm})$ and short $(2 \mathrm{~cm})$ length specimens. The 
macroscopic swelling, $\Delta \mathrm{V} / \mathrm{V}_{\mathrm{o}}$, of the specimen can be obtained with the approximate relation $\Delta \mathrm{V} / \mathrm{V}_{\mathrm{o}} \cong 3 \Delta \mathrm{L} / \mathrm{L}_{\mathrm{o}}$ where $\Delta \mathrm{L} / \mathrm{L}_{\mathrm{o}}$ represents the measured specimen length change $(\Delta \mathrm{L})$ normalized with the initial length $\left(\mathrm{L}_{\mathrm{o}}\right)[10]$.

As plotted in Figure 1, the response of ${ }^{238} \mathrm{Pu}$-enriched $\mathrm{Pu}$ alloys (enriched alloys) to self-irradiation near ambient temperature is volumetric expansion. The enriched alloys have increased in volume significantly, with the most of the increase occurring prior to $\sim 100$ equivalent years. This expansion in volume is a result of self-irradiation damage and follows the inverse exponential-type of expansion on time. These earlier results show that the volume expansion is primarily characterized by the accumulation of Frenkel pairs accompanied by in-growth of radiogenic helium in bulk plutonium alloys $[8,10,16]$.

Prior to $\sim 140$ equivalent years of age, both 2 and $3 \mathrm{~cm}$ length specimens show similar $\Delta \mathrm{V} / \mathrm{V}_{\mathrm{o}}$ values indicating minimal surface contribution (e.g. oxidation), and the volume change is therefore representative of the bulk material[10]. If only the bulk swelling accrues from the radiation damage, the dilatometry measurement will show $\Delta \mathrm{L}_{(2 \mathrm{~cm})} / \mathrm{L}_{\mathrm{o}(2 \mathrm{~cm})}=\Delta \mathrm{L}_{(3 \mathrm{~cm})} / \mathrm{L}_{\mathrm{o}(3 \mathrm{~cm})}\left(\right.$ or $\left.\Delta \mathrm{V}_{(2 \mathrm{~cm})} / \mathrm{V}_{\mathrm{o}(2 \mathrm{~cm})}=\Delta \mathrm{V}_{(3 \mathrm{~cm})} / \mathrm{V}_{\mathrm{o}(3 \mathrm{~cm})}\right)$. However, if the surface effects such as oxidation or interface reaction form significant surface layer, $\mathrm{L}_{\mathrm{s}}$, in addition to the bulk swelling, the fractional length change in the shorter specimen will be larger than the longer specimen, $\left(\Delta \mathrm{L}_{(2 \mathrm{~cm})}+\mathrm{L}_{\mathrm{s}}\right) / \mathrm{L}_{\mathrm{o}(2 \mathrm{~cm})}>\left(\Delta \mathrm{L}_{(3 \mathrm{~cm})}+\mathrm{L}_{\mathrm{s}}\right) / \mathrm{L}_{\mathrm{o}(3 \mathrm{~cm})}$. This behavior has been described in detail and tested using a surrogate cerium metal specimen [10].

As the self-irradiation time progresses (Fig. 1), we observe reduced rate of volume expansion after $\sim 100$ equivalent years of aging. A short-term rise after $\sim 140$ equivalent years for one of the sample is due to the instability in experimental instruments. At this point, the stability of the dilatometry unit for this sample could not be maintained to the 
earlier stability specification of $\pm 0.10 \mu \mathrm{m}$. Excluding this instability, the macroscopic expansions of both samples show apparent saturation between $\sim 100$ to $\sim 140$ equivalent years of aging, with peak expansion below $0.25 \%$. This behavior can be interpreted as due to reduced effects of the self-irradiation by alpha decay on the dimensional expansion at these extended ages. Past the 140 equivalent years of aging, our measurement shows a slight decrease in the volume expansion for the $3 \mathrm{~cm}$ length specimen, without any signs of void swelling.

Figure 2 shows results of immersion density measurements on the reference (identical composition to enriched alloys with the exception of the ${ }^{238} \mathrm{Pu}$ ) and ${ }^{238} \mathrm{Pu}$ enriched alloys. Included in the plot are the dilatometry data from figure 1 converted to density for comparison with the initial density set to $15.78 \mathrm{~g} / \mathrm{cm}^{3}$. The ages of reference samples for the immersion density range from 0.2 to 21 years. Large error bars in density data originates primarily from the effects of convection currents (heating) in the immersion fluid generated by the alpha decay of plutonium[10]. Following the initial stage showing the rapid decrease in the measured density, the rate of density reduction becomes reduced, similar to the reduced volume expansion rate from the dilatometry. The rate of decrease in the immersion density due to the helium in-growth is $\sim 0.002 \%$ per year which corresponds well with the measured volumetric swelling rate from the dilatometry[16]. Because of the large error bars in the density data, we do not observe the change in the rate of density decrease after $\sim 50$ equivalent years of age as in the dilatometry in figure 1 . The measurements past 90 equivalent years of age show minimal change in immersion densities. 
Both dilatometry and immersion density measurements show changes in physical properties of enriched Pu alloys induced by the self-irradiation damage but no evidence of void swelling. During the initial stage of aging, the volume expansion follows approximately the inverse exponential-type of expansion [10]. This macroscopic expansion has been attributed mostly to the lattice damage, remnant of the displacement cascades that the uranium recoils produce [18-22]. The amount of expansion in this case is approximately related to the number of Frenkel pairs that survive the radiation damage and subsequent recombination processes. This initial stage is observed in the current work up to about 2 equivalent years of aging, i.e. $\sim 0.2$ dpa. After the initial stage, the volume continues to expand although at a reduced rate. However, dimensional (length) changes are found to be significantly less by a factor of 2-3 compared to the changes in lattice parameters $[18,19,21,22]$. Wolfer et al. explained that a small fraction of gallium is segregated and precipitated to $\mathrm{Pu}_{3} \mathrm{Ga}$ (the $\zeta$-phase) $[18,20]$, creating smaller dimensional changes than the changes in lattice parameters. While it provides a possible explanation of the observed difference, more studies are needed to verify the proposed explanation, including experiments to measure the $\zeta$-phase precipitated in Pu alloys.

The accumulation of the actinide daughter products Am, $\mathrm{U}$, and Np needs to be considered. These products change both the lattice parameter and dimension equally. However, most of the dimensional and density changes will be caused by uranium daughters $\left({ }^{234} \mathrm{U}\right.$ and $\left.{ }^{235} \mathrm{U}\right)$ in ${ }^{238} \mathrm{Pu}$-enriched alloys. At the equivalent age of nearly 200 years ( 12 natural years), there is nearly 10 times more $\mathrm{U}$ compared to Am. Thus, Am makes a very minor contribution to the dimensional changes in enriched alloys [20]. The dimensional expansion behavior shown in Fig. 1 is dominated by the $\mathrm{U}$ daughters and 
helium bubbles. Wolfer et al. presented results that the expansion rate after the initial transient in the enriched alloy is equal to the expansion rate that typical ${ }^{239} \mathrm{Pu}$ materials will reach beyond 60 natural years [20]. However, this simple description does not explain the reduction in volumetric expansion after 100 equivalent years in enriched alloys. We need to better understand the combined contributions and integrated effects of the radiation induced defects and chemical changes in the plutonium materials, including tests using naturally aged plutonium materials.

\subsection{Quasi-static tensile}

Figure 3 shows the engineering stress-strain curves of enriched alloys (AA) and reference alloys (RA) at different ages. The yield and ultimate tensile strength at different ages from Figure 3 are plotted in Figure 4. As can be seen from the data, both mechanical properties are about the same between the reference and enriched alloys at the early stage of aging. Data is also consistent with the values expected for alloys with $\sim 2$ atomic $\%$ gallium [23]. While there is a difference in the total elongation between two alloys, both alloys show increase in strength and reduction in ductility from the aging process. Since

the last reported measurements near 90 equivalent years [16], the measurements to $\sim 150$ equivalent years continue to show gradual increase in strength, without signs of saturation as observed in dilatometry and immersion density. The ductility appears to reach around $10 \%$. Based on the present results, the aging process still increases static strength of $\mathrm{Pu}$ alloys without any detrimental failure in mechanical properties. It is clear that the continued increase in the static strength is mostly linked to the continued ingrowth of $U$ and helium in the enriched alloys. Studies of the integrated effect from in- 
grown actinide daughters and helium bubbles to microstructural changes are needed to explain the changes in the static strength.

\section{Summary and Conclusion}

The immersion density, dilatometry, and mechanical tests have been underway on plutonium alloys enriched with 7.3 atomic $\%$ of ${ }^{238} \mathrm{Pu}$ and reference plutonium alloys. In this report, we showed results from the self-irradiation equivalent time to nearly 200 years, nearly 100 years longer than in our previous papers. At this extended aging, both the immersion density and dilatometry show apparent saturation-like behavior of density and volume expansion, without signs of void swelling. The maximum volume expansion at $35^{\circ} \mathrm{C}$ is less than $0.25 \%$, and the immersion density appears to be stable around 15.73 $\mathrm{g} / \mathrm{cc}$. Quasi-static tensile measurement still show gradual increase in the static strength of

${ }^{238} \mathrm{Pu}$-enriched alloys with age. Results from our quasi-static physical property tests suggest a different contribution of defects depending on the time scale. This work reveals that it remains necessary to better understand an integrated contribution from several selfirradiation induced defects to Pu alloys. Studies of detailed microstructural and chemical investigation could clearly help to explain the changes occurring in plutonium materials with age.

\section{Acknowledgement}

This work performed under the auspices of the U.S. Department of Energy by Lawrence Livermore National Laboratory under Contract DE-AC52-07NA27344. 


\section{References}

[1] F. J. Freibert, D. E. Dooley and D. A. Miller, Journal of Alloys and Compounds 444 (2007) 320.

[2] W. G. Wolfer, Los Alamos Science 26 (2000) 274.

[3] S. S. Hecker, Los Alamos Science 26 (2000) 290.

[4] B. D. Wirth, A. J. Schwartz, M. J. Fluss, M. J. Caturla, M. A. Wall and W. G. Wolfer, MRS Bulletin 26 (2001) 679.

[5] N. Baclet, B. Oudot, R. Grynszpan, L. Jolly, B. Ravat, P. Faure, L. Berlu and G. Jomard, Journal of Alloys and Compounds 444 (2007) 305.

[6] M. J. Fluss, B. D. Wirth, M. Wall, T. E. Felter, M. J. Caturla, A. Kubota and T. D. de la Rubia, Journal of Alloys and Compounds 368 (2004) 62.

[7] S. M. Valone, M. I. Baskes and R. L. Martin, Phys. Rev. B 73 (2006).

[8] B. W. Chung, C. K. Saw, S. R. Thompson, T. M. Quick, C. H. Woods, D. J. Hopkins and B. B. Ebbinghaus, Journal of Alloys and Compounds 444 (2007) 329.

[9] B. W. Chung, S. R. Thompson and D. S. Hiromoto, Actinides 2008 - Basic Science, Applications and Technology 1104 (2008) 191.

[10] B. W. Chung, S. R. Thompson, C. H. Woods, D. J. Hopkins, W. H. Gourdin and B. B. Ebbinghaus, J. Nucl. Mater. 355 (2006) 142.

[11] V. V. Dremov, A. V. Karavaev, F. A. Sapozhnikov, M. A. Vorobyova, D. L. Preston and M. A. Zocher, J. Nucl. Mater. 414 (2011) 471.

[12] V. V. Dremov, F. A. Sapozhnikov, G. V. Ionov, A. V. Karavaev, M. A. Vorobyova and B. W. Chung, J. Nucl. Mater. 440 (2013) 278.

[13] V. V. Dremov, F. A. Sapozhnikov, S. I. Samarin, D. G. Modestov and N. E. Chizhkova, Journal of Alloys and Compounds 444 (2007) 197.

[14] A. J. Schwartz, M. A. Wall, T. G. Zocco and W. G. Wolfer, Philosophical Magazine 85 (2005) 479.

[15] S. K. McCall, R. E. Sykora, M. J. Fluss, B. W. Chung, G. F. Chapline and R. G. Haire, Physica B-Condensed Matter 403 (2008) 1225.

[16] B. W. Chung, S. R. Thompson, K. E. Lema, D. S. Hiromoto and B. B. Ebbinghaus, Journal of Nuclear Materials 385 (2009) 91.

[17] H. A. Bowman and R. M. Schoonov, Journal of Research of the National Bureau of Standards Section C-Engineering and Instrumentation C 71 (1967) 179.

[18] W. G. Wolfer, B. Oudot and N. Baclet, J. Nucl. Mater. 359 (2006) 185.

[19] N. T. Chebotarev and O. N. Utkina, in "Plutonium 1975 and other actinides", edited by H. Blank and R. Lindner (North Holland Publishing Co., Amsterdam, 1975) p. 559.

[20] W. G. Wolfer, A. Kubota, P. Soderlind, A. I. Landa, B. Oudot, B. Sadigh, J. B. Sturgeon and M. P. Surh, Journal of Alloys and Compounds 444 (2007) 72.

[21] C. Thiebaut, N. Baclet, B. Ravat, P. Giraud and P. Julia, J. Nucl. Mater. 361 (2007) 184.

[22] B. Ravat, B. Oudot and N. Baclet, J. Nucl. Mater. 366 (2007) 288.

[23] O. J. Wick, ed., Plutonium Handbook: A Guide to the Technology (American Nuclear Society, La Grange Park, IL, 1980). 


\section{Figure Captions}

Figure 1. The normalized volume changes for ${ }^{238} \mathrm{Pu}$-enriched alloys measured using dilatometry under helium atmosphere at $35^{\circ} \mathrm{C}$. A pair of 2 and $3 \mathrm{~cm}$ length specimens was tested. The time is represented as an equivalent aging time calculated by taking the measurement time and multiplying by the accelerating factor. The observed sharp rise in volume change after 140 eq. years for the $2 \mathrm{~cm}$ sample is due to the instrument's instability.

Figure 2. Immersion densities of both enriched and reference alloys showing the initial decrease in density followed by near saturation-like behavior at extended aging. Circles are reference alloys (RA) and squares are enriched alloys (AA). Dilatometry data from Figure 1 is converted to a relative change in density for comparison.

Figure 3. Tensile tests at room temperature show increase in the strength and decrease in the ductility as plutonium alloys are aged. RA is reference alloy and AA is enriched alloy.

Figure 4. Evolution of both engineering yield strength (YS) and ultimate tensile strength (UTS) for plutonium alloys from aging. Circles are reference alloys and squares are enriched alloys. 


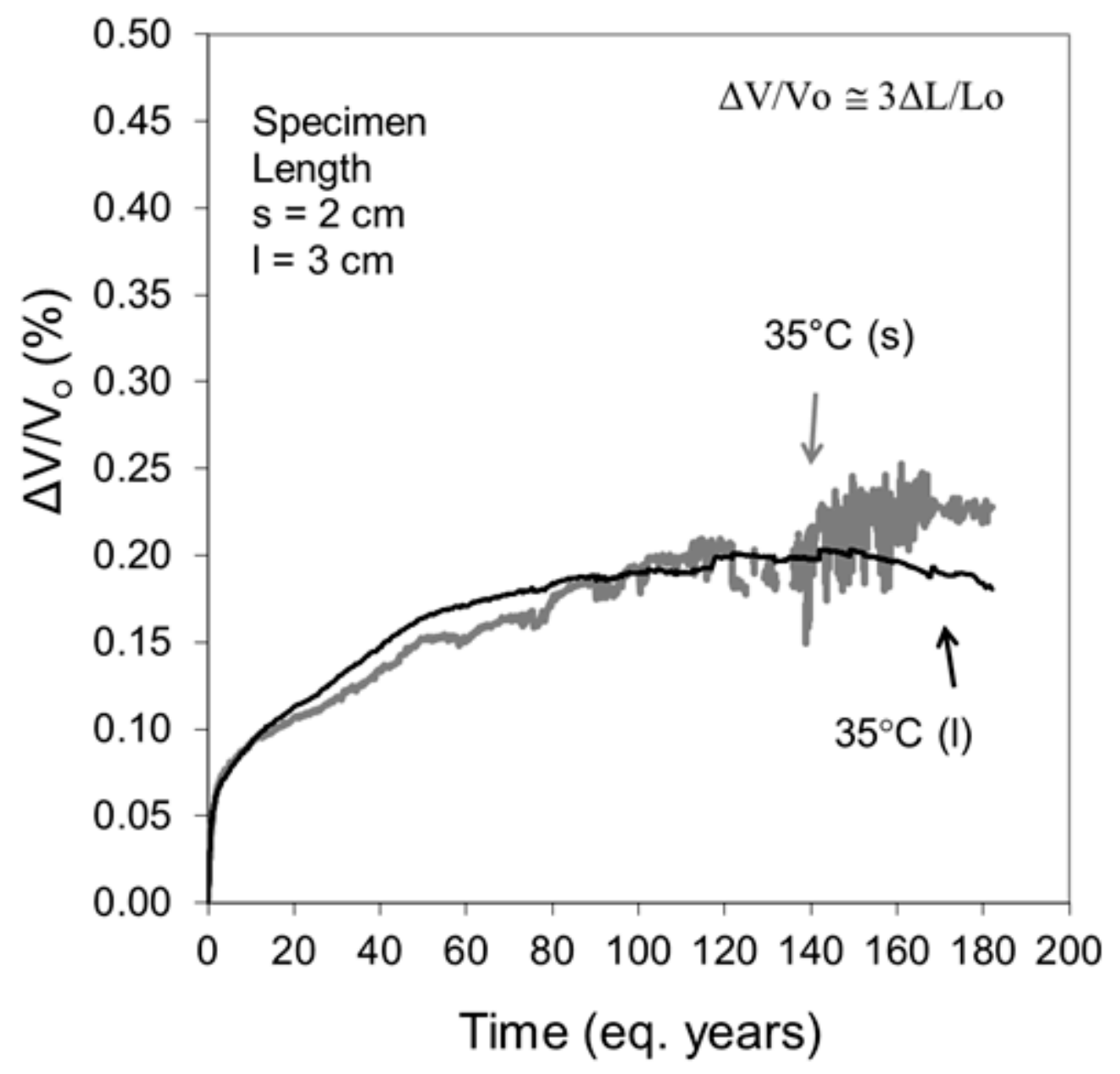

Figure 1 


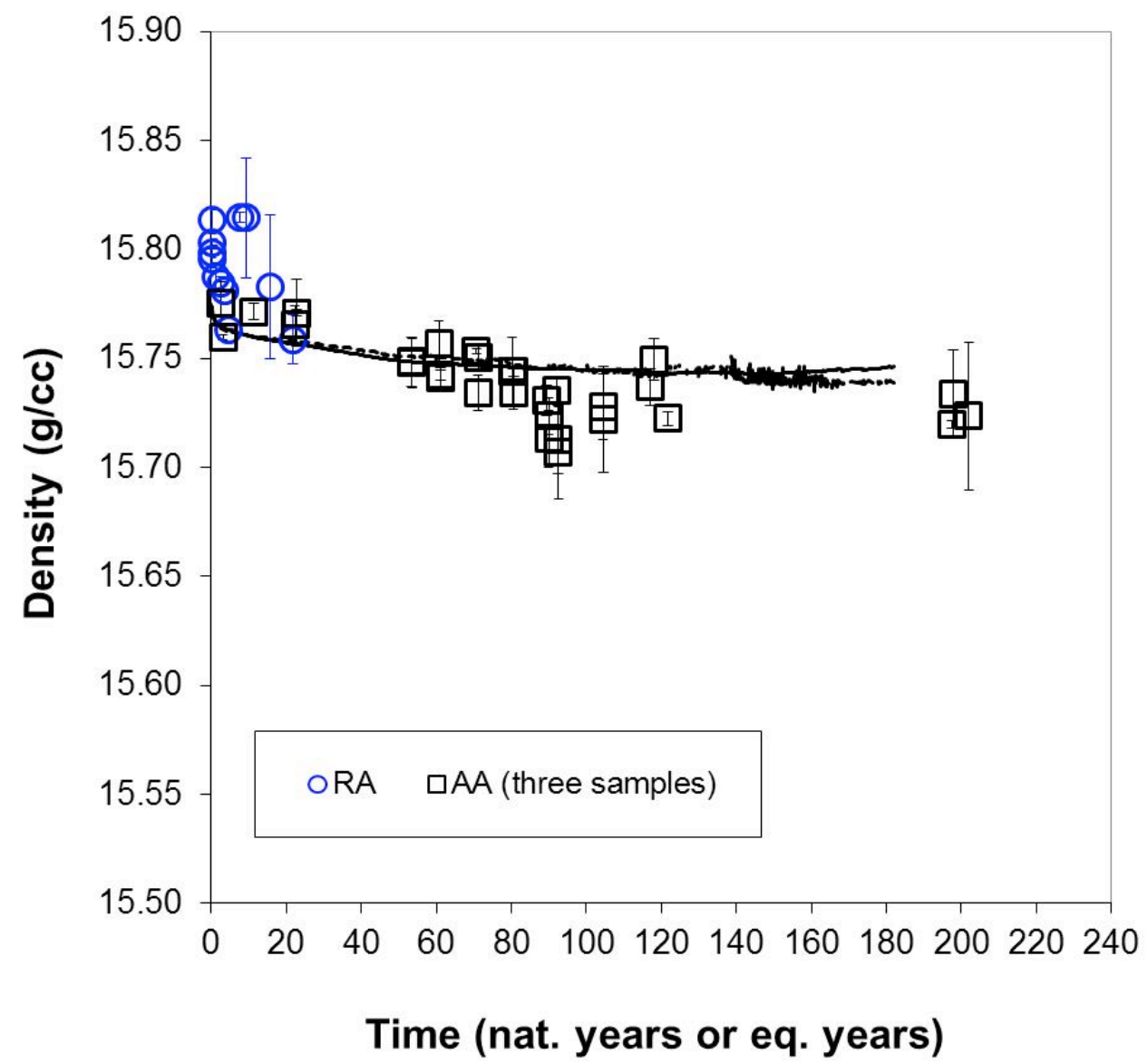

Figure 2 


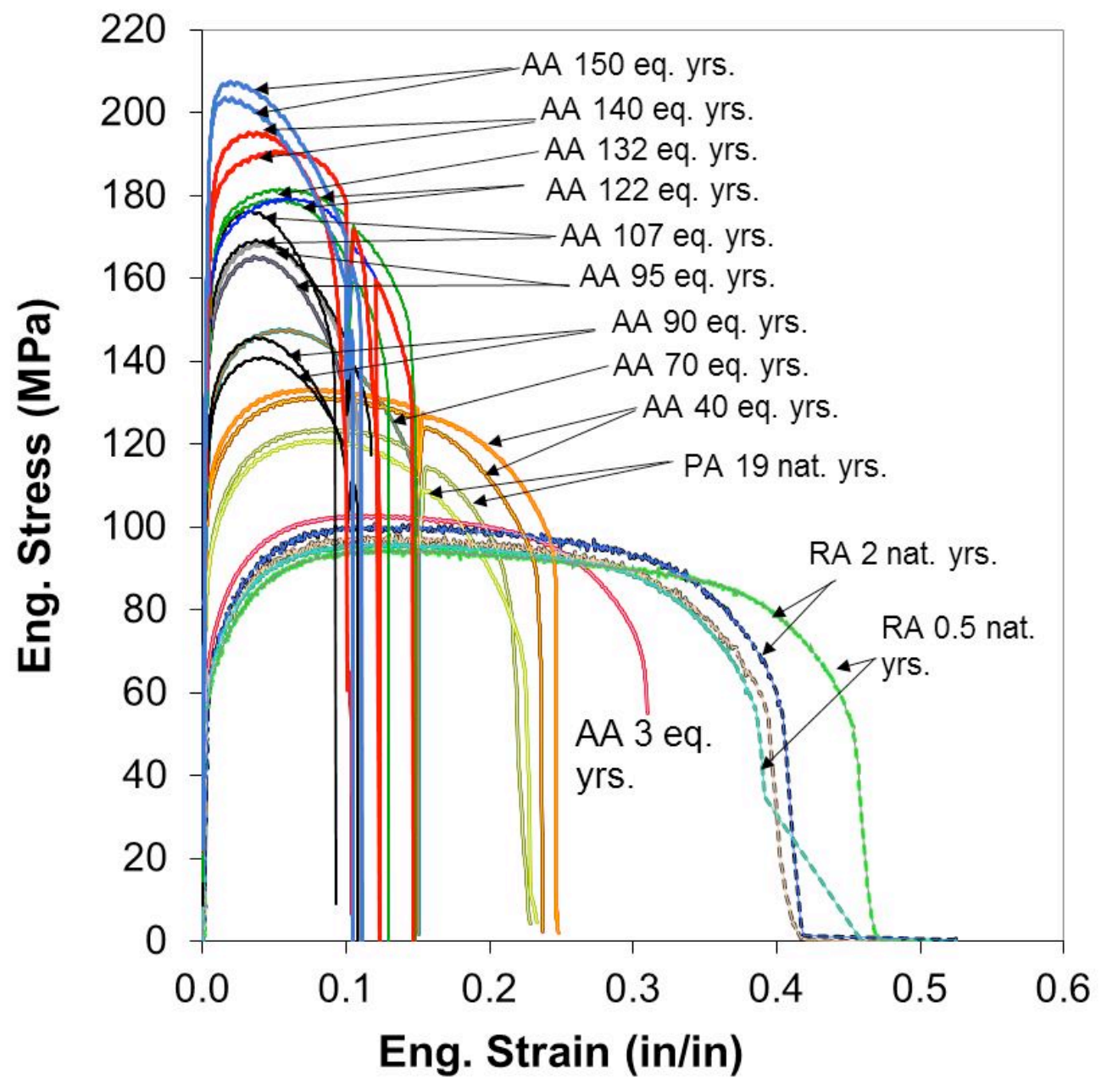

Figure 3 


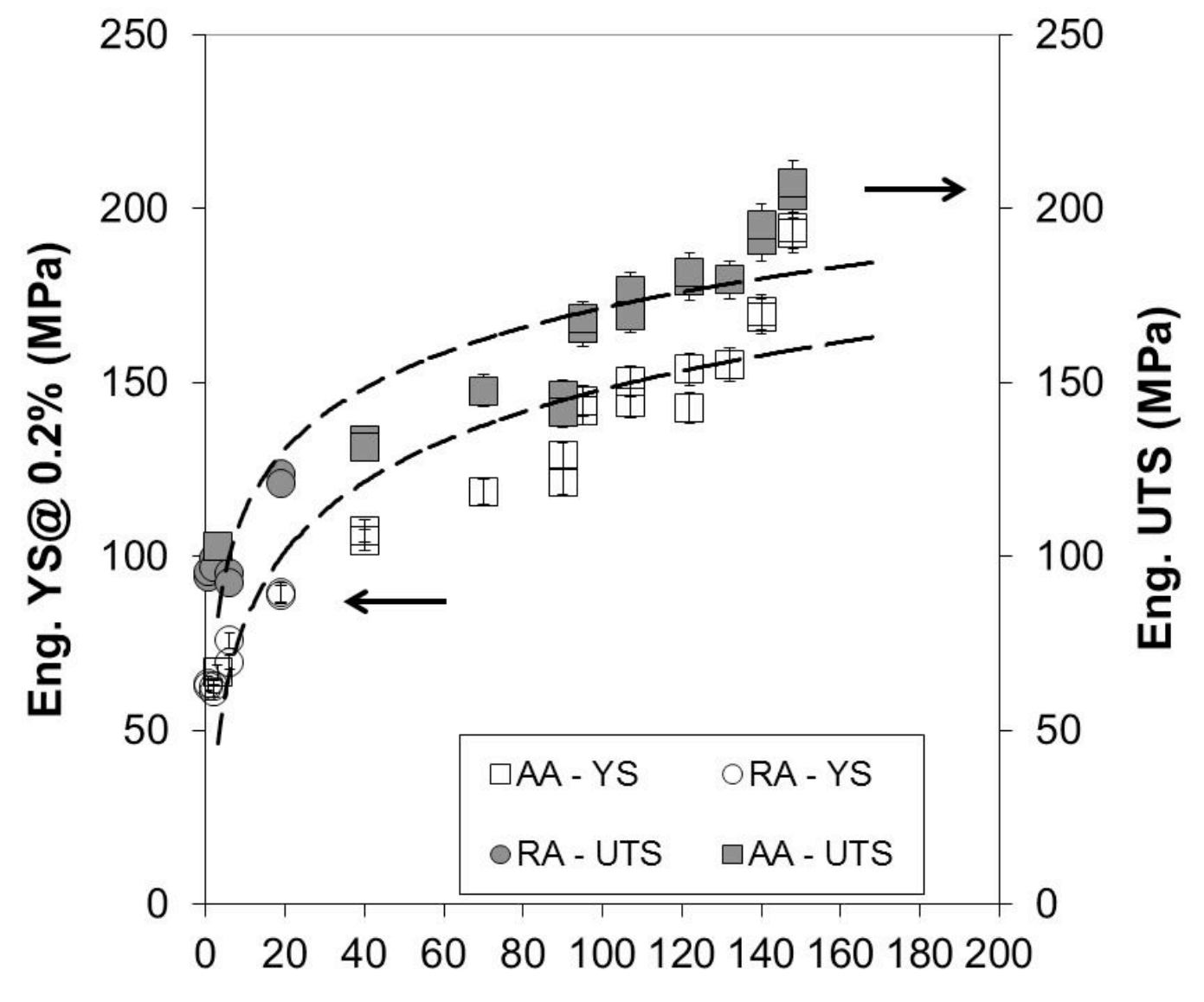

Time (nat. years or eq. years)

Figure 4 